\title{
Computer-Mediated Communication: Online Gaming Communication Culture
}

\author{
Aurora Almarini Khairunisa \\ Dept. of Communication Science \\ Universitas Indonesia \\ Jakarta, Indonesia \\ aurora.almarini@ui.ac.id
}

\begin{abstract}
Ease of internet access and the number of online games that can be downloaded on mobile phones, making online games growing rapidly in the community. The most popular genre played is the MMORPGs. MMORPG is an interactive game, where they are required to communicate with each other and share the results, both victory and defeat. Computermediated communication (CMC) in MMORPGs occurs between players who are in different places but placed in one team. CMC becoming a new culture of playing games together. The players usually judge other players from the conversation during the game, and because of the culture differences, it becomes something unique. Players realize it, eventually choose to compromise, commemorate, give direct punishment, or only play with people who have been known before, to avoid losing. Players understand the changes everyday-life communication after playing MMORPGs, which are more confident to speak a foreign language, accepting defeat, getting used to tolerating differences, and working together to achieve their goals.
\end{abstract}

Keywords-Online Games, Computer-Mediated Communicatio, Intercultural Communication

\section{INTRODUCTION}

Online-based games nowadays are very popular throughout the world for various purposes, such as entertainment, knowledge, education, or other reasons. In the last few decades, video games have become an increasingly popular form of entertainment for millions of people around the world. In particular, online games have become very popular[1]. The rapid development of the internet makes almost all electronic devices made can access the internet. Ease of internet access makes video games and online games easily accessible and played anywhere. Not only that, internet access also allows fellow users who are far apart to play together.

Statistics from Capcom shows that in April 2019, the market value of online PC games worldwide reached 33.6 billion USD [2]. Online game traffic worldwide reached 915 petabytes per month in 2016 and is expected to grow nine times from 2017 to 2022, where the Compound Annual Growth Rate (CAGR) or annual growth rate is 55 percent. Globally, online games traffic will be 4 percent of global IP traffic in 2022, up from 1 percent in 2017 [3]. Multiplayer based online games or multiplayer games have interesting features, namely the ability to communicate directly and in real time with other players. It allows players to communicate in real time with other players, through the text chat and voice chat features.
Most online-game players don't play alone; they collaborate with other players in completing a mission, or against an enemy. Although personal feelings such as interest, pleasure, and excitement are important motivations for joining an online first person shooter games (FPSGs), social interaction and competition are also important motivations for participating in such games [4]. People who play Massively Multiplayer Online Role Playing Games (MMORPGs) based games may know that in order to complete a "mission" or a large and epic task, players perform "raid" which involves many players [5]. In MMORPGs, traditional face-to-face communication has been replaced by computer-mediated communication. The rapid development of virtual communication technology is now very possible to re-create social reality in a "virtual environment", but can also make hyperreality [6].

There is nothing more prominent than the development of online games. MMORPGs have become a highly developed one, which was not initially considered on the market to be a daily life for most people, especially the three youngest generations [7]. Online gaming is a socio-cultural phenomenon, and something that will definitely not disappear in the near future, so this area is worthy of further investigation.

The internet supports various social interactions among individuals, groups and organizations, which provide new media for human expression, collaboration and exchange [8][9]. The shared use of technology supported by the Internet for social interaction is referred to as computer-mediated communication (CMC). Communication today takes place in cyberspace or virtual world, other than in the real world. Communication in the virtual world is done through electrical connections connected to the internet network. CMC is a concept that illustrates that communication is done with computer media. CMC is a widely accepted concept and has also been applied appropriately in the description of communication processes mediated by computers and through communication networks, such as the internet (Alexander, Dawson, \& Ichharam, 2006, p.241 in Norris, 2012). CMC is interesting because this concept looks at nationalism, cultural identity such as ethnicity and gender, and how it interacts with intercultural communication online [11]. Many modern video games and computer games allow players to interact with others in a virtual environment. This allows for a shared virtual environment (SVE), which allows people to experience together in the same computer room [12]. SVE is a unique space because advances in video games and computer 
technology have transformed games from solitary activities to inherent social activities [1].

The internet is a soft media that allows social and asocial use. People are not passively dictated by technology, but actively use technology to achieve their own goals [13]. This is consistent with SIP theory, which argues that the development of social relations is integrated in the context of computer-mediated communication (CMC) and face-to-face from time to time, because users actively adjust and develop adaptive strategies to use communication technologies that are appropriate to their relational goals [14]. If the theory is correct, users will actively choose and adapt to various choices on the internet.

Many studies have discussed the differences between CMC and face-to-face interaction in relation to work quality, productivity, and task satisfaction, social organization and intermittent communication tasks, and the effects of communication from supporting software for group decision making [15] [16] [17]. Research has begun to reveal how the communication process is influenced by CMC in instrumental tasks where the purpose of communication is to achieve a number of specific goals [18]

MMORPG players have different backgrounds because they all come from different parts of the country and culture. The cultural aspects brought by each player are not only visible from their behavior but also have a strong influence on the attitude and organization of their groups [6]. Basically, culture encompasses all human experience. Culture is a shared and communal experience of the world of a group of people, how do they structure experiences; and how they organize and guide their reactions to those experiences and their interactions with the world [19]. Martin \& Nakayama (2011) elaborates further on the main characteristics of culture, as follows:

- Culture is learned. Culture in general is not something that is born with humans, but is a way of looking at the world, reacting to perceptions learned from experience, and from others.

- Culture is perception and values. Culture involves perceptions and values. It is about how people see the world, and what they value and consider important.

- Culture involves feelings. Culture is not just about observing and thinking about the world, but about feeling the world. It is about people's emotions and their affective processes regarding people and the world around them.

- Culture is shared. Culture is not something held by one person, it is something shared among people, hereditary.

- Culture is communication. Because culture is something that is shared, it is something that is created in communication. Culture does not exist in everyone, but in interactions and exchanges between people. That's what they say, share, and do with each other.

- Culture is behavior. Culture is not just about how people see the world, how they perceive things and how they feel about them, but about how they react to this perception, it's about what they do, how they do it, and with whom.

- Culture is dynamic and heterogeneous. Culture is human, and culture is communication. These things keep on changing. As people age, and as a new generation becomes prominent, culture develops to adapt to their various perceptions, feelings, values and behavior.

The description of the cultural characteristics initiated by Martin \& Nakayama above will help to develop a framework for examining culture in a virtual context that occurs in MMORPGs. Every player in MMORPGs will coordinate with each other, therefore in every game communication process is very possible.

Communication in MMORPGs is a major factor in creating an effective "attack". Not only the ability to communicate with others, but also how to make others listen and understand what we are trying to convey, so they can do what they should do [6]. The communication structure, both at the team or guild level during the completion of the mission or task, is shown directly on the player's avatar according to their respective roles. As in DOTA 2, there are five known roles, namely hard carry, midlaner, offlaner, roaming support and hard support. The division of roles in DOTA functions so that a team has the right composition to achieve victory. Each role has its own function and task. Hard carry has a crucial role, where it becomes the key to victory at the end of the game. Midlaner is a role that is in the middle position, which is considered to be able to do a good team fight. Offlaner has a role that is almost similar to midlaner, but by fighting more enemies. Roaming support plays a role in protecting the team from opposing heroes. Hard support is basically "backing" from the team, taking into account the state of the enemy around, paying attention to what items the enemy has, and providing various items the team needs. Each role has its advantages and they will be very useful at certain times. There will always be a time when the fate of a team will depend on one role, so teamwork and communication must go well.

\section{Methodology}

The study was conducted for one full month in May 2019. Data collection was carried out through interviews and observations which were used as primary data. Interviews were conducted with three informants selected through purposive sampling. The three informants chosen did not know each other, but routinely played the same online games; DOTA 2 and PUBG. DOTA 2 is a game that has been entered into the category of e-sports or electronic sports which ranks first among e-sport tournaments around the world [2]. PUBG is one of the rising royale battle genre games. June 2018 counted as many as 50 million players, and reached 3.2 million players who actively played in one hour at peak times [21]. Observations were made by watching while the informant was playing, both DOTA and PUBG. Observation is carried out without disturbing the informant's game. Secondary data collection was also carried out from the study of literature from several literatures related to research. The sources of literature used in this study are from various journals and results of statistics from related company websites. 
The paradigm used in this research is constructivist. The constructivist paradigm is used to understand how the players construct the reality of MMORPGs. The cultural and environmental settings of individual players shape the way individuals see things, including the way individuals feel things, shape the way individuals see things, which gives individuals a fairly clear view of the world. The qualitative approach was chosen in this study because this study requires exploration / listening from the subject and build understanding based on the results of the exploration.

The research method used in this study is constructivism. The constructivism method was chosen because the focus was the unique experience of each informant, without analyzing the informant's background in depth [22].

The analysis technique used is interactive, among others by means of data reduction, data presentation and drawing conclusions. This study uses triangulation as a data validity test technique by cross-testing the results of interviews with the results of observations and related literature

\section{RESULT}

Interviews were conducted with three informants face to face. The informants have different educational backgrounds, namely students, undergraduate, and postgraduate. The three informants reside in three different cities; Bandung, Palembang and Jakarta. Informants were chosen based on their interest in DOTA and PUBG online games. The initial survey to find out what online games are the most widely played, was done through question sticker feature on Instagram. DOTA and PUBG were the answers most frequently written by respondents. Then the disarming is done by selecting the people who write the two games, which means they play both DOTA and PUBG.

After being discharged, there were 10 of the respondents who played the two games. Furthermore, personal communication is carried out to each respondent to ask about their willingness to be interviewed and observed while playing. After screening based on accessibility (informant's ability, location and time of research), the 10 respondents narrowed to 3 people; IF, VC, and CY. Although not all informants reside in Jakarta, interviews are conducted in Jakarta at the request of the informants themselves. IF informant is a 24-year-old medical student who has completed postgraduate education at Monash University, and is currently a co-assistant doctor in Jakarta. Interviews and observations were conducted at Watt Coffee, a cafe located on the ground floor of IF's apartment. The VC informant is 23 years old and is a law graduate who now works as an assistant legal consultant in a private office in Bandung. When getting a visitation assignment to Jakarta, VC are willing to be interviewed and observed while playing PUBG. Furthermore $\mathrm{CY}$ informant who is 22 years old is a final year student at the Faculty of Psychology, and is domiciled in Palembang. Had a chance to get a psychological test and interview for a beauty products company, CY informants came to Jakarta and when there was free time was taken to relax in a café for interviews and observations while playing. Observation from the three informants was done by looking at their game for two consecutive games, which took a total time for two games around 1-1.5 hours.
After collecting data and analyzing data, it was found that the third reason informants played DOTA and PUBG was to "killing time", get pleasure, and as a means to gather with friends. The informant hopes that by playing DOTA and PUBG there will be pleasure and satisfaction because of gathering with friends in between busy activities.

Informants also felt the benefits gained from playing DOTA and PUBG, partly because the two games can meet their expectations. Informants are aware of CMC in DOTA and PUBG, which can be done through text chat and voice chat. The most common communication is through voice chat because it is considered effective and gives a different impression when you can hear the voice of a team player directly.

The informants are aware of the different cultural backgrounds of each player who is in a team, both known and unfamiliar people. Therefore, observations and adaptations are made at the beginning of the game to see the flow of the players who then assist the informant in determining the appropriate treatment for other players. In addition, the results also obtained that playing DOTA and PUBG influenced their communication in the real world, both in the direction that was considered positive or negative.

In this study, several findings were described that illustrate the experiences of the informants as active players of DOTA and PUBG MMORPGs. The informant's experience was obtained from the results of playing for more than 3 months, and with a total playing time of around 300 hours. IF have been playing DOTA since 2014 and PUBG since January 2019, VC have been playing PUBG since February 2019 and CY is playing DOTA since 2015. Based on the research results, there are several categories that describe the experiences of the informants in playing DOTA and PUBG.

\section{A. Online games as a new media.}

As we get older, the busyness of each person will vary. From the beginning in the same school or office and having the same activities everyday, must be separated because of the different career paths chosen. This makes the friendship group have to find other ways to stay able to get the latest news from their friends. The most commonly used method is to use social media. Lots of information can be found on social media, and one of them is to find out how others are doing. Based on interviews with informants, there are other ways to gather friends, namely through online games. Games that require teamwork are considered to be more fun when done with friends themselves, especially those who are considered close friends.

Motivation in playing MMORPG DOTA and PUBG varies. In addition to IF who is looking for happiness in the midst of busy activities, there are also VC who play to fill the break time when she is not working. For her, playing is a way to kill time effectively because one game can spend more than 30 minutes. In the midst of VC's free time, she plays online games to make herself busy.

Unlike the two previous informants, CY considers that MMORPGs are a fun game because they are considered competitive. For him, online games can help hone his competitive spirit in a fun way. In other words, CY found that online games became one of the media for learning selfdevelopment. 
Playing MMORPGs was felt by informants to help in some learning, including being more confident when speaking a foreign language, learning to accept defeat, getting used to tolerance of differences, and working hand in hand in teams to achieve goals.

\section{B. Culture in a virtual environment MMORPGs}

The virtual environment that is formed in MMORPG DOTA and PUBG is not always the same for everyone. Motivation of each person in playing is different, thus forming a different perception of the virtual environment that is created. Everyone brings a different culture. Culture in the real world is not always the same as culture in cyberspace. Culture in MMORPGs is not something that emerges suddenly, but is a reaction from learning from one's own experience or from others

The features provided in the form of voice chat are not a new culture, but a developing culture. With the voice chat feature, the culture of playing together feels more real because they can listen and talk in real-time, according to VC.

Unlike VC, CY even more often communicate directly because of their culture by playing together in the same place. $\mathrm{CY}$ and his friends often have adequate time and space to gather together so they prefer to gather in the same place if they want to play together.

Culture involves the values and perceptions of individuals. What is valued and considered important becomes its own view. Similar to $\mathrm{CY}$ and his friends who prioritize togetherness rather than comfort, where even though the playground feels less comfortable, they still choose to survive instead of playing together but not in the same place.

Informants are aware of cultural differences from each player. Culture is not only observing and thinking about the world, but also how to feel it. Individual emotions and affective processes towards others around them, shapes culture. IF assume that when other people get angry, which is something that might be considered negative for others, is considered funny to him. Where VC do not like people who get angry especially if they still considered a noob. CY did not really think that getting angry was something that needed to be exaggerated, he assumed that expressing resentment was a human thing and should be respected.

Culture is something that is formed in communication. Culture is not within an individual but is in the process of interaction itself. When someone says, shares, or does something, that is culture. Understanding other people's cultures is not always easy, especially if we unconsciously stereotyped others.

They also have stereotypes of some other people's cultures. Culture is behavior, which is not only how things are viewed or how they feel about things, but how they react to perceptions, what they do, how and with whom. Culture is dynamic and heterogeneous, it can develop, can adjust to individual perceptions, feelings, values, and behavior. Each individual has his own preferences about his views on others, including the views of informants towards people from other cultures who play in MMORPGs.
Many studies have discussed the differences between $\mathrm{CMC}$ and face-to-face interaction in relation to work quality, productivity, and task satisfaction, social organization and intermittent communication tasks, and the effects of communication from supporting software for group decision making [15]-[17]. Research has begun to reveal how the communication process is influenced by CMC in instrumental tasks where the purpose of communication is to achieve a number of specific goals [18]

\section{CMC through online games as an alternative}

Aside from being entertainment, free time and learning media, online games are also considered to have other functions, namely as an alternative to gathering with friends. Online games are considered to be able to replace face-to-face meetings which may be difficult to do because of the busyness of each activity. Offline meetings have now been replaced by meetings in cyberspace, especially in the virtual world of games. The thing that is considered fun is when friends in the same circle play the same game so they can play together and become a team.

In the past, playing console games with friends had to be in the same place and coordinate with each other by talking directly. The concept is the same as playing as then, only now there is no limit on distance and time, all can play together anywhere and anytime, as long as they could freeing up time. Communication that occurs is exactly the same, can be done by talking directly. The difference is now the communication process that occurs is mediated by a computer.

Online games also have other functions; as a place to form new friendships. Usually when they play on themselves the game will find other players to become their teammates. Team members not always come from the same country, they could be from other countries as long as their on the same server.

Getting stranger as teammate is a common thing in DOTA and PUBG. When playing solo, the game will make match making with other solo-player. If during the "war" the team members were fun and reliable, it would considered as a pleasure for the members to get to know each other and even become friends.

The theory of social information processing believes that the development of social relations is integrated in the context of CMC and face to face directly from time to time because the user will adjust and develop strategies in adapting to communication technology in accordance with the objectives. Users actively choose and adapt to the various choices available on the internet. This research shows the active behavior of the informants in choosing something on the internet according to their purpose, for example when one informant chooses to bring the far ones closer by gather online, or the other option when the informant chooses to play online games with their friends at the same place that doesn't really need CMC during the game.

\section{CONCLUSION}

Culture in MMORPGs is not something that emerges suddenly, but is a reaction from learning from one's own experience or from others. The culture that occurs in CMC which is done through MMORPGs is formed from experiences, perceptions, feelings, and communication carried out during the game by each individual. Culture is behavior, 
which is not only how things are viewed or how they feel about things, but how they react to perceptions, what they do, how and with whom. Culture is dynamic and heterogeneous, it can develop, can adjust to individual perceptions, feelings, values, and behavior. Each individual has their own preferences about their views on others, including the views of informants towards people from other cultures who play in MMORPGs.

Other than that, although online games often seen as negative because they are considered a waste of time, actually have several benefits, namely (1) as a momentary pleasure, (2) as one of the choices for leisure time, (3) developing a competitive spirit, (4) stay in touch with friends, (5) build new friendships, (6) learn foreign languages, (7) learn tolerance, cooperation, and grace when you lose. I hope this study can be developed further in the future considering there are still many possibilities and uniqueness of CMC in this digital era.

\section{REFERENCES}

[1] J. H. Kuznekoff and L. M. Rose, "Communication in multiplayer gaming: Examining player responses to gender cues," New Media Soc. vol. 15 , no. 4 , pp. 541-556, 2013.

[2] W. co. WePC, "2019 Video Game Industry Statistics, Trends \&amp Data - The Ultimate List," 2019. [Online]. Available: https://www.wepc.com/news/video-game-statistics/\#online-gaming. [Accessed: 21-May-2019].

[3] V. N. I. Cisco System, "Cisco Visual Networking Index: Global Mobile Data Traffic Forecast Update, 2017-2022 White Paper - Cisco,” 2019. [Online]. Available: https://www.cisco.com/c/en/us/solutions/collateral/serviceprovider/visual-networking-index-vni/white-paper-c11738429.html\#_Toc953338. [Accessed: 21-May-2019].

[4] P. Gloor, H. J. Lee, J. W. Kim, J. Choi, and S. J. Park, "Communication, Opponents, and Clan Performance in Online Games: A Social Network Approach," Cyberpsychology, Behav. Soc. Netw., vol. 16, no. 12, pp. 878-883, 2013.

[5] F. M. Chee, "Online games as a medium of cultural communication: An ethnographic study of socio-technical transformation," p. No Pagination Specified, 2012.

[6] M. Kańuża and E. Golik, "Intercultural communication and the Internet. The role of intercultural communication in Internet societies.," Tarpkultūrinè Komun. Ir Internetas Tarpkultūrinès Komun.
Vaidmuo Interneto Bendruomenèse., vol. 45, pp. 22-34, 2008.

[7] G. Crawford, V. K. Gosling, and B. Light, Eds., Online Gaming in Context : the Social and Cultural Significance of Online Games. New York: Routledge, 2011.

[8] S. Kiesler, Ed., Culture of the Internet. Mahwah, NJ, US: Lawrence Erlbaum Associates Publishers, 1997.

[9] J. B. Walther and J. K. Burgoon, "Relational Communication in Computer-Mediated Interaction," Hum. Commun. Res., vol. 19, no. 1, pp. 50-88, Sep. 1992

[10] A. R. Norris, "Computer-Mediated Communication and Globalization: Considering Social, Academic, and Business Factors," Inq. Jpurnal, vol. 04, no. Business \& Communication, 2012.

[11] C. Ess and F. Sudweeks, "Culture and Computer-Mediated Communication: Toward New Understandings," J. Comput. Commun., vol. 11, pp. 179-191, 2006.

[12] R. Schroeder, "Being There Together and the Future of Connected Presence," Presence Teleoperators Virtual Environ., vol. 15, no. 4, pp. 438-454, Aug. 2006.

[13] J. A. Bargh and K. Y. A. McKenna, "The Internet and Social Life," Annu. Rev. Psychol., vol. 55, no. 1, pp. 573-590, Jan. 2004.

[14] J. B. Walther, "Computer-mediated communication: Impersonal, interpersonal, and hyperpersonal interaction.," Communic. Res., vol. 23, no. 1, pp. 3-43, 1996.

[15] S. G. Straus and J. E. McGrath, "Does the medium matter? The interaction of task type and technology on group performance and member reactions.," J. Appl. Psychol., vol. 79, no. 1, pp. 87-97, Feb. 1994.

[16] R. E. Rice and G. Love, "Electronic Emotion: Socioemotional Content in a Computer-Mediated Communication Network," Communic. Res., vol. 14, no. 1, pp. 85-108, Feb. 1987.

[17] J. E. McGrath and A. B. Hollingshead, Groups interacting with technology: Ideas, evidence, issues, and an agenda. Thousand Oaks, CA, US: Sage Publications, Inc, 1994

[18] J. Peña and J. T. Hancock, "An analysis of socioemotional and task communication in online multiplayer video games," Communic. Res., vol. 33, no. 1, pp. 92-109, 2006

[19] G. Roos and M.-M. Bezuidenhout, "Online Gaming: A Realisation of the Utopian Intercultural Communication Environment," Ммит, 2016.

[20] J. N. Martin and T. K. Nakayama, Experiencing intercultural communication : an introduction. New York, NY: McGraw-Hill, 2011.

[21] 2019 Statista, "• PUBG global player base 2018 | Statistic," 2019. [Online]. Available: https://www.statista.com/statistics/791791/pubgplayer-base-world/. [Accessed: 24-May-2019].

[22] M. Q. Patton, "Two Decades of Developments in Qualitative Inquiry: A Personal, Experiential Perspective," Qual. Soc. Work, vol. 1, no. 3, pp. 261-283, Sep. 2002 